\title{
Assessment of Intension to Voluntary HIV Counseling and Testing Utilization and Associated Factors Among Youth Living in Mizan Aman Town, South-West Ethiopia By Health Belief Model, A Cross Sectional Study
}

\author{
Medhanit Worku Zewude ${ }^{1} \quad$ Tadesse Gebremedhin*2 Adissu Gebremariam Gole $^{3}$ \\ Shimeles Wondimu Kebede ${ }^{4}$ Efrem Negeri kostiyabe, ${ }^{4}$ Yazachew Moges ${ }^{4} \quad$ 'Gashaw Temesgen ${ }^{4}$ \\ 1.Lecturer and coordinator of Gender Affairs, Mizan-Aman Health science college, southwest Ethiopia \\ 2.Lecturer Jimma university, institute of health, college of public health epidemiology department \\ 3.Mierab Omo zone Health department, southwest Ethiopia \\ 4.Assistant Lecturer Mizan-Aman Health science college, southwest Ethiopia
}

\begin{abstract}
Background: - Voluntary Counseling and Testing (VCT) services have become one of the most common means of preventing, detecting and improving access to care and support to HIV/AIDS. Currently in Ethiopia, young people are most affected group of HIV/AIDS. Moreover, youth VCT utilization is low in studies among university students. Therefore, this study was aimed to assess youth's voluntary counseling and testing utilization and associated factors in Mizan-Aman Town, Southwest Ethiopia. Community based cross sectional study was conducted among youth living in Mizan-Aman Twon. The data was collected using pre-tested interviewer administrating questionnaires using simple random sampling technique. Descriptive statistics, bivariate analysis, multivariate logistic regressions ware used accordingly. A total of 389 youths responded the questionnaire making the response rate of $96.6 \%$. Two hundred thirty five $(60.4 \%)$ were female. VCT utilization was $42.4 \%(95 \%$ $\mathrm{CI}=37.8 \%, 47.6 \%$ ). Factor associated with intension to VCT service utilization are females $[\mathrm{AOR}=1.69,95 \% \mathrm{CI}=$ (1.017-2.814)]; attending secondary education level $(\mathrm{AOR}=2.099,95 \% \mathrm{CI}=(1.12-3.929))$ and attending college education level $(\mathrm{AOR}=3.39,95 \% \mathrm{CI}=(1.783-6.45))$; And having low perceived barrier and cue to action are $[\mathrm{AOR}=2.63,95 \% \mathrm{CI}(1.236-5.614)$ and $[\mathrm{AOR}=10.85,95 \% \mathrm{CI}=(6.05-19.46)]$ respectively. Being female, educated, high perceived barrier and cue to action were identified as significant associated factors for intension to utilize voluntary counseling and testing. More emphases should be given by concerned bodies in Mizan-Aman town health unit, Mizan Aman Health Science College on information translation regarding VCT, focus on male youth, collaborating with educational sectors, and assuring youth to benefit more on VCT services.
\end{abstract}

Keywords: Voluntary Counseling and Testing (VCT), Mizan-Aman, Youth.

DOI: $10.7176 / \mathrm{JMPB} / 66-03$

Publication date:June 30th 2020

\section{Introduction}

Until the start of HIV/AIDS epidemic to still, it continues to be internationally a public health concern. A total of 77.3 million people have become infected, $45 \%$ of them have died of opportunistic infections. Within one year (2017) around 37 million were living with HIV/AIDS. Among these one fourth of them don't recognize that they are infected and deaths associated with AIDS related illnesses still existed. Ethiopia is among one of 17 African countries which accounts highest numbers of new HIV infections(Musheke et al., 2013).

Unlike adult, children and youth have different understanding of HIV/AIDS issues and different vulnerability to HIV infection. So, people in range of 15 - 24 years account more than half of cases globally(Baggaley, 2002; FMOH, 2007; WHO, 2015).

Children and youth have unique vulnerability to HIV infection, and as their ability to comprehend HIV/AIDS issues differs from that of adults(FMOH, 2007). Knowledge of HIV status assists people make specific decisions to reduce risk and increase safer sex practices so that they can remain disease free. Among those who are HIV infected, their knowledge status allows them to take action to protect their sexual partners, to access treatment, and to plan for the future(FMOH, 2016).

Voluntary HIV counseling and testing is the process whereby an individual or couples undergo counseling to enable them to make an informed choice about being tested for HIV. This decision must be entirely the choice of the individual/s and they must be assured that the process will be confidential(Baggaley, 2002).

Ethiopia is one of the Sub Saharan countries highly affected by HIV/AIDS pandemic. According to Federal HIV/AIDS Prevention and control Office in Ethiopia, PLWHA was estimated at 738,048 and the prevalence rate was estimated around $1.3 \%$. HIV/AIDS is affecting productive part of the population. Young people aged 15-24 years are at the fore front of the HIV/AIDS epidemic, they are vulnerable to and at risk of HIV because of the strong influence of peer pressure and the development of their sexual and social identities, engagement in unprotected sex, contamination associated drug use, exposure to blood and blood products, or unsterilized skin- 
piercing procedures(FMOH, 2016).

Because young people naturally reflect their communities, the variety of their behaviors and practices is diverse in the same way as adults'. Knowing how young people are infected and affected by HIV/AIDS in a given context is important in developing effective service delivery models. VCT services may have to be general or targeted depending on a range of factors including HIV prevalence, health-seeking behaviors, and level of stigma, access to hard-to-reach groups and supportive legal and policy environments(Baggaley, 2002).

In recent years, a number of African countries have employed national campaigns to boost utilization of HIV testing and counselling (HTC) services. Ethiopia has a rapidly growing population of adolescents and youth, more than one third of the estimated total population of 110 million. So, the Ethiopian Government has also formulated the youth development package with the view to alleviate the economic, social and political problems of youth and youth policy addresses a wide range of youth issues, ranging from HIV/AIDS to environmental protection and social services(Dambisya, 2007; ENAP, 2016).

Different research findings in Ethiopia revealed that utilization of voluntary counselling and testing service is low and its level of utilization varies among different segments of the population(Humnesa, 2018). EDHS (2016) shows that the adult population counselled and tested for HIV was 37\% and 38.2\% for young people aged 15-24 years(FMOH, 2016). Knowledge about HIV and VCT, presence of confidential testing, willingness to have VCT, perceived importance of VCT, perceived risk of HIV, being sexually active and socio demographic factors are some factors related to VCT utilization(Dagne et al., 2017). Examining and understanding factors contributing to VCT uptake is a vital and timely activity to facilitate HIV prevention and control effort, these factors are expected to differ among youth. However the uptake of VCT utilization in study area were still unknown.

Therefore, this study assessed the intension to VCT service utilization and associated factors among youths in Mizan-Aman town.

\section{Research Methodology}

\subsection{Study area and Design}

A community based cross-sectional study was conducted in Mizan Aman town which is located in Southwest direction, $561 \mathrm{~km}$ far from Addis Ababa, the capital city of Ethiopia. According to Mizan Aman town municipality and Health Office 2017/18 G.C data, youth population accounted 5495 women and 4416 men in a five administrative Kebeles. In this town there were several unemployed adults and there is only one youth friendly center. This study was conducted from March 10 to April 8/ 2019 G.C.

\subsection{Study population and sampling procedure}

In this study the participants aged 15-24years and can fulfill inclusion criteria were our study population. The sample size was calculated by Epi-info software by single population proportion formula by taking prevalence for VCT utilization $64.3 \%$ from a study conducted in Birbir town, Gamo Gofa zone, Ethiopia(Gebremeskel, 2017). $Z=1.96,95 \%$ confidence level, $5 \%$ margin of error. After considering $15 \%$ non-response rate, the final sample size was 407. Before deciding this sample size, we computed sample size for factors and compared. From calculated sample sizes we took the largest one which is 407 .

Among five kebeles found in Mizan-Aman town administration, two of them were selected by simple random sampling method by considering their socio-demography and socio economic homogeneity of the community. Then households with young was identified and coded after taking sampling frame from health extension workers. By using systematic random sampling technique, study participants were selected. In 32 households there were more than two youths in each house hold and we used lottery method to select one of them.

\subsection{Data collection}

A structured questionnaire was used to collect information from youth by trained graduate class health information technician students. Two days training was given for data collector and supervisor on the objective of the study, method of data collection and content of questionnaire to avoid any ambiguity at the time of data collection. The completeness of data was checked by supervisor during data collection time and after data collection by the principal investigator.

The overall data collection was supervised by midwife and nurse technical assistants from Mizan Aman Health Science College. Data were collected through face to face interview method. The health belief model questionnaire was adapted and modified from research done by Zelalem Mehari (Mehari, 2015). Reliability test for HBM subscale and knowledge questions to HIV were calculated using and revealed Cronbach's alpha in acceptable range (greater than 0.75 ).

To assure the quality of the questionnaire, it was prepared first in English and then translated into Amharic (local language) and then re-translated back to English by different language experts. Before conducting the actual study, the Amharic version questionnaire was pretested on $5 \%$ of total sample size (20 youths) at a Birken ketema (15KM far from actual study area) which had similar characteristics with Mizan-Aman town. The pretest was used 
to revise its clarity of questionnaire, order of question, skip patterns, its consistency, time estimation for data collectors and participant willingness to responses. It also assisted as to easy determine number data collectors for specified/estimated study period.

\subsection{Measurement}

Dependent variable was utilization of voluntary counseling and testing within 12 months of data collection date for HIV/AIDS. Youth who tested and get services within the given duration (within 12 moths before study started) were grouped in utilized. Independent variables in this study were sociodemographic factors (sex, age, marital status, religion, ethnicity, residence and educational status), knowledge on HIV/AIDS, and perception of study participants on VCT by using six construct health belief model questions (perceived susceptibility, perceived severity, perceived benefit, perceived barrier, perceived self-efficacy and cues to action).

Participants who scored above mean in knowledge questions were categorized as knowledgeable. Individuals who scored above the mean in each six constructs of HBM questionnaire were categorized in high perceived susceptibility, high perceived severity, high perceived benefit, high perceived barrier, high self-efficacy, and high motivation for cues to action and scored below the mean value categorized as low perceptions for each constructs.

\subsection{Data Analysis}

The data was cleaned, coded and entered in to Epi-data version 3.1 then exported to SPSS version 20 for analysis. Descriptive summaries were described by tables and pie chart. Bi-variable logistic regression was carried out initially to identify the candidate variables for multivariable logistic regression. All variables with the p-value of $<0.20$ were candidates and entered into the multi-variable logistic regression model for controlling the possible effects of confounders. Odds ratio with $95 \%$ confidence interval was calculated and the variable with P-value of $<0.05$ was declared as statistically significant. During multi-variable logistic regression, Hosmer Lemshew goodness of fit test for model fitness was conducted and its p-value was reported as 0.413 .

\subsection{Ethical Consideration}

Ethical clearance was obtained from the research and publication office of Mizan Aman Health Science College. Informed written consent was obtained from either respondents for greater or equal to 18years old or parents for less than 18 years old, after the necessary explanation about the purpose, benefits and also their right on decision of participate in the study. The assurance of confidentiality was kept by using separate room to store collected data and using pass word during analysis.

\section{Result}

\subsection{Socio-demographic characteristics}

A total of 389 youth live in Mizan-Aman town were interviewed and included in the analysis, making response rate $95.6 \%$. Females accounted 235(60.4\%) of the participants. The median age of the respondents was 19 years. Orthodox religion followers accounted $198(50.4 \%)$ of the participants followed by Protestant $150(38.6 \%)$. By ethnic composition Bench and Amhara comprises 104(26.7\%) and 101 (26.0\%) of participants respectively. One hundred sixty nine $(69.2 \%)$ of the participants were rural background by residence. Regarding educational status; $146(37.5 \%)$ were attended secondary level of education. One hundred $(25.7 \%)$ participants had attended primary level education. Concerning marital status; majority of them $301(77.4 \%)$ were single (Table 1).

\subsection{Comprehensive knowledge about HIV/AIDS and perception level about VCT of Respondent}

From the total participants, three hundred eighty $(81.7 \%)$ were scored above the average for knowledge questions of HIV/AIDS prevention and were considered as knowledgeable. Regarding the perception, $137(35.2 \%)$ of the respondents had high perceived susceptibility to HIV/ADIS. Only fourteen $(3.6 \%)$ respondent had high perceived benefit to VCT, 329(84.6\%) had less perceived self-efficacy to VCT (Table 2)

\subsection{Practice of voluntary HIV counseling and testing of respondents}

From the total participants, two hundred ninety six $(76.1 \%)$ had ever practiced VCT. Among these, one hundred sixty five $(42.6 \%)$ of participants were practiced VCT in the past 12 months and heard the result of VCT (Figure 2).

\subsection{Factors associated with VCT utilization of youth in Mizan-Aman Town, southwest-Ethiopia, 2019.}

For bi-variable logistic regression analysis, a total of thirteen variables were entered. Among these nine variables age, sex, religion, educational status, residence, knowledge on HIV/AIDS, perceived benefit, perceived barrier and cue to action were candidate variables at $p$-value $<0.20$ for multi-variable analysis.

In multi-variable logistic regression analysis, from nine candidate variables, only four (sex, educational status, perceived barrier and cue to action) were significant predictors of VCT practice. According to multi-variable 
logistic regression analysis, VCT practice was two times more likely in female participants than male participants $[\mathrm{AOR}=1.69,95 \% \mathrm{CI}=(1.017-2.814)]$. Attending secondary and above college education level participant was two and three times more utilized VCT than participant attending primary level education $[\mathrm{AOR}=2.099,95 \% \mathrm{CI}=(1.12$ 3.929 ) and $[\mathrm{AOR}=3.393,95 \% \mathrm{CI}=(1.783-6.45)]$ respectively. Having low perceived barriers and cue to action was two and ten times utilized VCT than the counter partner having high perceived barriers and low cues to action $[\mathrm{AOR}=2.63,95 \% \mathrm{CI}(1.236-5.614)$ and $[\mathrm{AOR}=10.85,95 \% \mathrm{CI}=(6.05-19.46)]$ respectively(Table 5).

\section{DISCUSSION}

Youth VCT utilization varies and low in different African countries. According to this study VCT uptake is $42.4 \%$. Current study showed almost consistent finding with EDHS 2016 and with different studies. Study done among in Bahirdar, Ethiopia is in line with our result which showed that $37.8 \%$ of study participants were tested and in Nakuru, Kenya revealed that only $37.4 \%$ of out of school youth are utilized VCT. In contrast with this finding, VCT uptake of different university students like Arbaminch (61.5\%), Wolkite (65.7\%) and Ambo (67.2\%) were higher. This might be due to as they are university students they have an opportunity to get information focused particularly on VCT and pressured by their peers. Additionally as reported in different literatures educational status have had positive influence on VCT uptake. In other hand this discrepancy could be the type of tool they used (Fikadie, Bedimo and Alamrew, 2014; Bekele et al., 2015; Mehari, 2015; FMOH, 2016; Ayugi et al., 2017; Dagne et al., 2017).

The current study revealed that sex of youth is an important predictor for the utilization of VCT service. Female participants are 1.7 times utilize VCT than male participants $[\mathrm{AOR}=1.69,95 \% \mathrm{CI}=(1.02-2.81)]$. This finding is consistent with study done in Arusha, Tanzania, reveals female youth is 1.8times more to utilize VCT than male study participants $(\mathrm{AOR}=1.895 \% \mathrm{CI}=(1.2-2.8)$. This might be associated with females frequently visit health facilities for reproductive health surmises like family planning, ANC, and labour and delivery. This might increase their chance to have VCT more frequently than male. This finding is not consistent with study done in Anchar district, west Hararghe, Ethiopia reveals male youth were five times more to utilize VCT than females $(\mathrm{AOR}=5.25,95 \% \mathrm{CI}=(1.065,25.87) \mathrm{P}=0.042)$ this might be Ethiopian males are easily accessed services than women (Ayehu, Kassaw and Hailu, 2016; Ansha et al., 2017; Dagne et al., 2017).

Current study revealed that educational status is associated with uptake of VCT among youths. This is supported by different studies; study conducted in university students showed that the participants' level of education or batch is associated with VCT utilization. Study in Bahir-dar University revealed that an increased batch of study in university has increased odds of having VCT. This study is in line with study conducted in Bahirdar university and rural areas of Ethiopia: youths completed secondary education is almost 2 times more likely to be tested than completed primary education $(\mathrm{OR}=2.1)$ and being second year student is $2.7(1.74,4.22)$ times more likely to be tested HIV than first year (Ansha et al., 2017). This consistency might be due to their ease access to information, reading different books, magazines, internet and soon. This all might increase their intention to be tested. Additionally we can also justify this; as their educational status increase, they easily exchange different experiences from different experts.

This study showed that perceived barrier $\mathrm{OR}=2.496(1.355-4.59)$ is significantly associated with VCT. It is consistent with different studies conducted in, Arba-minch and Debre-Markos. Among associated constructs of barriers studied in these areas fear of HIV-related stigma, fear of positive result, long waiting time in testing place and perceived health workers' inability to maintain confidentiality are the major barriers(Tsegay, Edris and Meseret, 2013). Similarly a systematic review in Sub-sharan Africa on factors enabling and deterring uptake of VCT, study done Birbier town, Ethiopia, and Debre-Markos University shows that the respondents who heard about confidential HIV testing were 3.6 times more likely to be tested than their counterparts (AOR $=3.66,95 \%$ $\mathrm{CI}(2.00,4.89)$ and $(\mathrm{AOR}=2.5,95 \% \mathrm{CI}=(1.289,3.889) \mathrm{P}=0.018)$ and $(\mathrm{AOR}=3.00,95 \% \mathrm{CI}=(1.65,5.49) \mathrm{P}=0.001)$ respectively $(20,23,32)$. Institution based cross sectional study in Deber-Markos University, Ethiopia explained that perceived stigma to HIV has positive association with VCT utilization( $\mathrm{AOR}=1.3,95 \% \mathrm{CI}=(1,1.6), \mathrm{P}=0.01$ ) (Tsegay, Edris and Meseret, 2013).

Additionally, systematic review revealed that perceived poor quality of health services as characterized by inability by health workers to maintain confidentiality, perceived poor caliber of health workers and lack of trust in testing technologies inhibit uptake of testing(Ayugi et al., 2017).

As per this study, respondent, who had high cue to action was more than ten times utilized VCT than the counter partner having low cue to action $[\mathrm{AOR}=10.85,95 \% \mathrm{CI}=(6.05-19.46)]$. This finding is similar with other study in Arusha, Tanzania and Bahir-dar University, Ethiopia showed that individuals who discussed issues of HIV/AIDS frankly with a sexual partner, peer encouragement about HIV testing and knowing someone infected is positive influence on VCT utilization (Tsegay, Edris and Meseret, 2013; Meremo et al., 2016; Teklehaimanot et al., 2016). This might be associated with youth's decision was relatively relied on others. Information acquires from their families, peers and medias and printing material might influence youth judgment. Other reason might be peers encouragement or open communication decrease the fear of testing associated with youth's perceived 
stigma and discrimination by creating confidence.

\section{Strength and limitation of the study}

We used valid and consistent tool. Even though the tool is valid and consistent, using HBM increases subjectivity. As we collected self-report data, this might increase social desirability bias. There might be also recall bias particularly in case of outcome variable. As we used cross sectional study design we can't assess cause and effect relationship.

\section{CONCLLUSSION and RECOMENDATION}

\subsection{Conclusion}

This study showed that VCT uptake among youths is in line with EDHS 2016 report. But still it is very low when we compare it with 90-90-90 strategy of 2030 HIV/AIDS prevention; as developing country the uptake of VCT should be at least $78 \%$ at this time. Being female, educated, having perceived barrier and higher cues to action have positive significant association with voluntary counseling and testing.

\subsection{Recommendation}

\section{Mizan Aman town health unit}

* Should support and improve youth friendly services, provide opportunity for youth information by radio, television, magazines, mini Medias focusing on VCT. Additionally create opportunity to share experiences from their peers, HIV positive individuals who are on ART.

* Should give emphasis on voluntary counseling and testing to achieve 90-90-90 strategy of 2030 for youths especially for males.

* Should encourage youth education in collaboration with educational sector as education is significantly associated with their intention to test.

* Should give strong and careful awareness on their perception specially perceived barriers gaps like stigma, confidentiality, waiting time, pain during testing. Even though there are some barriers in health facilities youth should be informed that risk benefit analysis. Should actively support health facilities and give awareness on these barriers with health extension workers, responsible health care workers around these kebeles.

\section{Mizan Aman Health Science College}

* Should give focus and support on community education regarding VCT uptake particularly perception on

\section{Researchers} barrier and cues to action by team training program and radio program.

\# We recommend that analytical research should be conducted by using objective tools.

Competing Interest

There is no competing interest

Author's contribution

Medhanit Worku and Tadesse Gebremedhin conceptualized the research problem, designed the study, analyzed data, drafted and revised the paper for publication. Shimelis Wondimu, Yazachew Moges and Efrem Negeri were involved in data collector training, data entry and implementation of the study and co-writing and revision of the paper. Addisu Gebremariam and Gashaw Temesgen involved in collecting baseline line data. All authors reviewed and approved the final draft.

\section{Acknowledgement}

We would like to acknowledge Mizan Aman college of Health Science for financial support and we would like to acknowledge data collectors and supervisors. Lastly but not the least, we Thank study participants for their kindest cooperation.

\section{References}

Ansha, M. G. et al. (2017) 'Reproductive Health Services Utilization and Associated Factors Among Adolescents in Anchar District, East Ethiopia', Journal of Family and Reproductive Health?, 11(2).

Ayehu, A., Kassaw, T. and Hailu, G. (2016) 'Level of Young People Sexual and Reproductive Health Service Utilization and Its Associated Factors among Young People in Awabel District, Northwest Ethiopia', PLOS, pp. 1-11. doi: 10.1371/journal.pone.0151613.

Ayugi, J. et al. (2017) 'Assessment of Voluntary HIV Counseling and Testing Service Utilization and Associated Health Service Related Factors Among Out of School Youth in Nakuru Kenya : A Cross Sectional Survey', Public Policy and Administration Research, 7(10), pp. 45-52.

Baggaley, D. B. and R. (2002) VOLUNTARY COUNSELING AND TESTING (VCT) AND YOUNG PEOPLE A SUMMARY OVERVIEW

Bekele, G. E. et al. (2015) 'Assessment of Knowledge, Attitude, Practice and Determinants of VCT Utilization for HIV / AIDS Among Ambo University Students, West Shoa Zone , Oromia Region, Ethiopia : Cross Sectional Study', Science Journal of Public Health, 3(2), pp. 259-264. doi: 10.11648/j.sjph.20150302.25. 
Dagne, S. et al. (2017) 'AIDS \& Clinical Research Voluntary Counseling and Testing Utilization and Associated Factors', Journal of AIDS \& Clinical Research, 8(6), pp. 6-11. doi: 10.4172/2155-6113.1000704.

Dambisya, Y. M. (2007) 'Equity in Health in A review of non-financial incentives for health worker retention in east and southern Africa', Regional Network for Equity in Health in east and southern Africa, (44).

ENAP (2016) 'National Child Health Strategy - Every Newborn Action Plan ( ENAP ) Maldives'.

Fikadie, G., Bedimo, M. and Alamrew, Z. (2014) 'Prevalence of Voluntary Counseling and Testing Utilization and Its Associated Factors among Bahirdar University Students', Hindawi Publishing Corporation Advances in Preventive Medicine, 2014.

FMOH (2007) Guidelines for HIV Counselling and Testing in Ethiopia.

FMOH (2016) EDHS.

Gebremeskel, F. (2017) 'Assessment of Voluntary HIV Counselling and Test Utilization and Associated Factors among Youth People in', American Journal of Nursing Science, 6(6), pp. 440-446. doi: 10.11648/j.ajns.20170606.11.

Humnesa, K. (2018) 'Evaluating the Practices of Media Relations in Federal HIV / AIDS Prevention and Control Office ( FHAPCO )', in.

Mehari, Z. (2015) 'DEVELOPMENT OF HIV TESTING BELIEF SCALE (HTBS) AND APPLICATION OF HEALTH BELIEF MODEL (HBM) TO PREDICT HIV TESTING INTENTION AND BEHAVIOUR AMONG UNIVERSITY STUDENTS IN ETHIOPIA'.

Meremo, A. et al. (2016) 'Tanzania : experience from Angaza Zaidi programme', Pan African Medical Journal, 8688, pp. 1-12. doi: 10.11604/pamj.2016.23.189.5683.

Musheke, M. et al. (2013) 'A systematic review of qualitative findings on factors enabling and deterring uptake of HIV testing in Sub-Saharan Africa', $B M C$.

Teklehaimanot, H. D. et al. (2016) 'Factors influencing the uptake of voluntary HIV counseling and testing in rural Ethiopia: a cross sectional study', BMC Public Health. BMC Public Health, pp. 1-13. doi: 10.1186/s12889-016-2918-z.

Tsegay, G., Edris, M. and Meseret, S. (2013) 'Assessment of voluntary counseling and testing service utilization and associated factors among Debre Markos University Students, North West Ethiopia : a cross-sectional survey in 2011'.

WHO (2015) 'Adolescent Health Research Priorities : Report of a Technical Consultation 13th and 14th October 2015', (October), pp. 1-22.

Table 1: Summary of socio-demographic characteristics of youth living in Mizan-Aman town, southwest-Ethiopia, $2019(\mathrm{n}=389)$.

\begin{tabular}{|l|l|l|}
\hline Variables & Number & Percent \\
\hline Sex & & \\
\hline Female & 235 & 60.4 \\
\hline Male & 154 & 39.6 \\
\hline Age & & \\
\hline $15-19$ & 151 & 38.8 \\
\hline $20-24$ & 238 & 61.2 \\
\hline Religion & & \\
\hline Orthodox & 198 & 50.4 \\
\hline Muslim & 35 & 9 \\
\hline Protestant & 150 & 38.6 \\
\hline Catholic & 8 & 2.4 \\
\hline Ethnicity & & \\
\hline Bench & 104 & 26.7 \\
\hline Kaffa & 92 & 23.7 \\
\hline Oromo & 24 & 6.2 \\
\hline Amhara & 101 & 26 \\
\hline Tigrie & 23 & 5.9 \\
\hline Other ${ }^{1}$ & 45 & 11.6 \\
\hline Place of Residence & & \\
\hline Urban & 120 & 30.8 \\
\hline Rural & 269 & 69.2 \\
\hline Educational status & & 25.7 \\
\hline Primary education & 100 & 37.5 \\
\hline Secondary education & 146 & \\
\hline & & \\
\hline
\end{tabular}




\begin{tabular}{|l|l|l|}
\hline Variables & Number & Percent \\
\hline College \& above & 143 & 36.8 \\
\hline Marital status & & \\
\hline Single & 301 & 77.4 \\
\hline Married & 84 & 21.6 \\
\hline Divorced & 4 & 1 \\
\hline
\end{tabular}

Other 1 : Dizi, Welayta, Sheko, Sheka, Gurage

Table 2: Summary of comprehensive knowledge about HIV/AIDS and perception level about VCT of respondents living in Mizan-Aman town, southwest-Ethiopia, $2019(n=389)$

\begin{tabular}{|l|l|l|}
\hline Variables & Number & Percent \\
\hline Knowledge about HIV/ADIS & & \\
\hline Knowledgeable & 318 & 81.7 \\
\hline Less knowledgeable & 71 & 18.3 \\
\hline Perceived susceptibility & & 35.2 \\
\hline High susceptibility & 137 & 64.8 \\
\hline Low susceptibility & 252 & \\
\hline Perceived severity & & 11.8 \\
\hline High perception on severity & 46 & 88.2 \\
\hline Low perception on severity & 343 & \\
\hline Perceived benefits & & 3.6 \\
\hline High benefits & 14 & 94.4 \\
\hline Low benefits & 375 & \\
\hline Perceived barrier & & 87.1 \\
\hline High barrier & 339 & 12.9 \\
\hline Low barrier & 50 & \\
\hline Perceived self-efficacy & & 15.4 \\
\hline High self-efficacy & 60 & 84.6 \\
\hline Low self-efficacy & 329 & \\
\hline Cue to action & & 38.6 \\
\hline High motivation & 150 & 61.4 \\
\hline Low motivation & 239 & \\
\hline
\end{tabular}

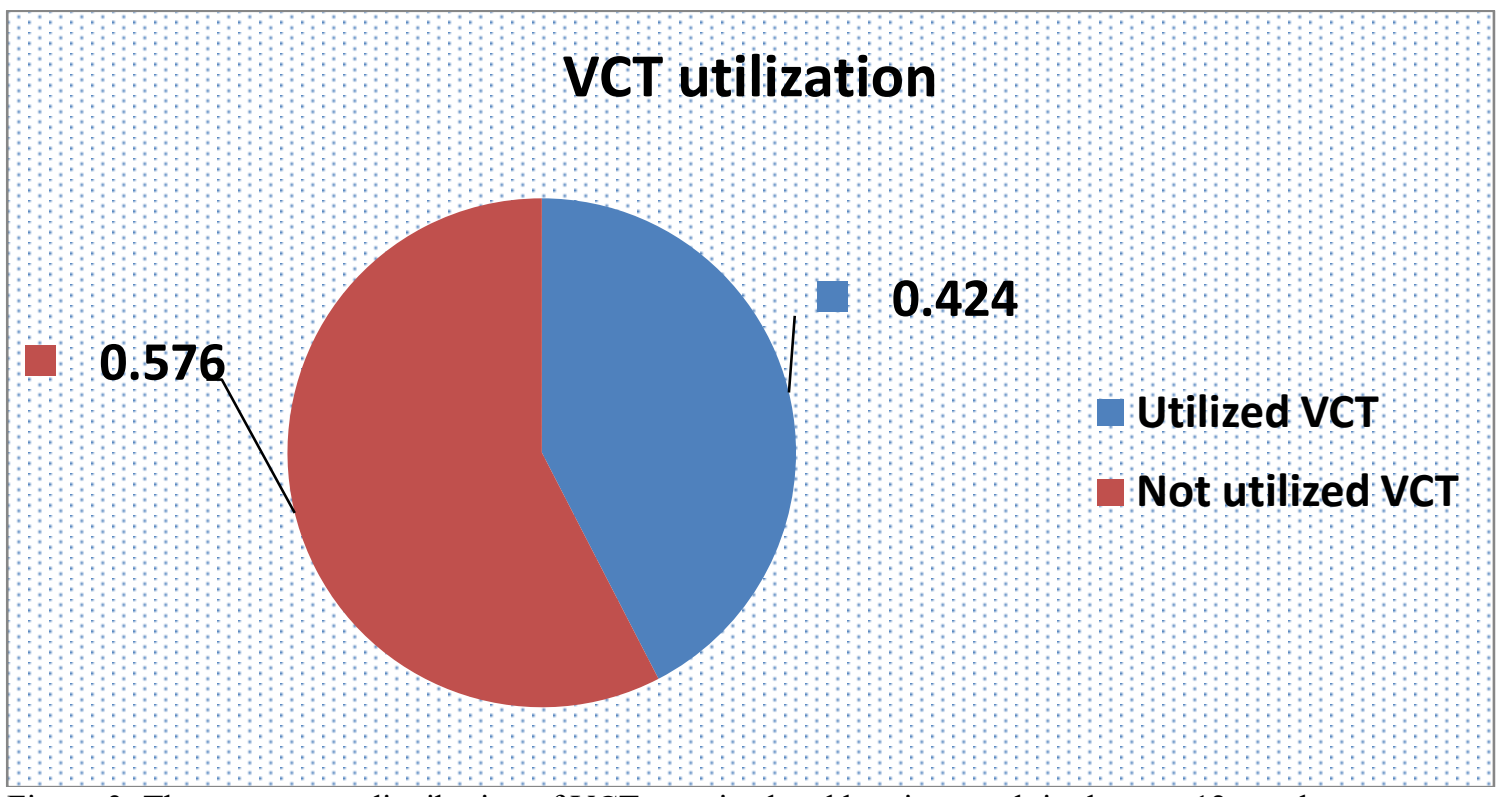

Figure 3: The percentage distribution of VCT practiced and hearing result in the past $12 \mathrm{months}$ 
Table 5: Multi-variable logistic regression analysis result of the study conducted among youth Mizan-Aman Town, Southwest Ethiopia, 2019.

\begin{tabular}{|c|c|c|c|c|}
\hline \multirow[t]{3}{*}{ Variables } & \multicolumn{2}{|c|}{ VCT Practice Status } & \multirow{3}{*}{$\begin{array}{c}\text { COR } \\
\text { (with } 95 \% \mathrm{CI} \text { ) } \\
\end{array}$} & \multirow{3}{*}{$\begin{array}{c}\text { AOR } \\
\text { (with } 95 \% \mathrm{CI} \text { ) } \\
\end{array}$} \\
\hline & & & & \\
\hline & Yes & No & & \\
\hline \multicolumn{5}{|l|}{ Sex } \\
\hline Male & $73(44.3 \%)$ & $81(36.2 \%)$ & $.54(.32-.917) * *$ & 1 \\
\hline Female & $92(55.7 \%)$ & $143(63.8 \%)$ & 1 & $1.69(1.02-2.81)^{*}$ \\
\hline \multicolumn{4}{|l|}{ Age } & \\
\hline $15-19$ & $42(25.5 \%)$ & $109(48.7 \%)$ & 1 & \\
\hline $20-24$ & $123(74.5 \%)$ & $115(51.3 \%)$ & $.12(.060-.22)^{*}$ & \\
\hline \multicolumn{4}{|l|}{ Religion } & \\
\hline Orthodox & $81(49.1 \%)$ & $115(51.3 \%)$ & $1.21(.58-1.94)$ & \\
\hline Muslim & $14(8.5 \%)$ & $21(9.3 \%)$ & $1.11(.55-1.85)$ & \\
\hline Protestant & $63(38.2)$ & $87(38.8 \%)$ & $0.81(0.61-1.25)$ & \\
\hline Catholic & $7(4.2 \%)$ & $1((0.6 \%))$ & 1 & \\
\hline \multicolumn{5}{|l|}{ Educational status } \\
\hline Primary education & $56(33.9 \%)$ & $44(19.6 \%)$ & $.30(.16-.57)^{* *}$ & 1 \\
\hline Secondary education & $56(33.9 \%)$ & $90(40.2 \%)$ & $.64(.35-1.17)$ & $2.1(1.12-3.93)^{*}$ \\
\hline College $\&$ above & $53(32.2)$ & $90(40.2)$ & 1 & $3.4(1.78-6.45)^{* *}$ \\
\hline \multicolumn{4}{|c|}{ Knowledge status on HIV/ADIS } & \\
\hline Knowledgeable & $136(82.4 \%)$ & $188(83.9 \%)$ & 1 & \\
\hline Less knowledgeable & $35(17.6 \%)$ & $36(17.1 \%)$ & $.62(.32-1.20)$ & \\
\hline \multicolumn{4}{|l|}{ Perceived benefits } & \\
\hline High benefits & $9(5.5 \%)$ & $5(2.3 \%)$ & 1 & \\
\hline Low benefits & $156(94.5)$ & $219(97.7 \%)$ & $.93(.25-3.40)$ & \\
\hline \multicolumn{5}{|l|}{ Perceived barrier } \\
\hline High barrier & $134(81.2 \%)$ & $205(91.5 \%)$ & 1 & 1 \\
\hline Low barrier & $31(18.8 \%)$ & $19(8.5 \%)$ & $.16(.93-5.003)$ & $2.63(1.24-5.61)^{*}$ \\
\hline \multicolumn{5}{|l|}{ Cue to action } \\
\hline High motivation & $102(61.8 \%)$ & $48(22.5 \%)$ & $11.51(6.3-21.2)^{* *}$ & $10.85(6.05-19.46)^{* *}$ \\
\hline Low motivation & $42(38.2 \%)$ & $176(78.5 \%)$ & 1 & 1 \\
\hline
\end{tabular}

$* *$ P-value $<0.001, *$ P-value $<0.05,1$-Reference category

COR-Crude odds ratio, AOR-Adjusted odds ratio 